\title{
Responses of tomato (Solanum lycopersicum L.) plants to iron deficiency in the root zone
}

\author{
María Rocío Jiménez ${ }^{1 *}$, Laura Casanova ${ }^{1}$, Teresa Saavedra ${ }^{2}$, Florinda Gama ${ }^{2}$, \\ María Paz Suárez', Pedro José Correia ${ }^{2}$, Maribela Pestana ${ }^{2}$ \\ ${ }^{1}$ Departamento de Ciencias Agroforestales, ETSIA, Universidad de Sevilla \\ Carretera de Utrera, km 1, 41013 Sevilla, Spain \\ ${ }^{2}$ MeditBio-Center for Mediterranean Bioresources and Food, University of Algarve \\ FCT, Ed8, Campus of Gambelas, 8005-139, Faro, Portugal
}

\begin{abstract}
Iron deficiency induces a yellowing in the aerial part of plants, known as iron chlorosis, and reduces the growth, yield, and quality of the fruits. Understanding plant response to iron deficiency is essential for agronomic management. This study decoded the temporal response of tomato plants (Solanum lycopersicum L.) to iron deficiency by quantifying different vegetative parameters. Subapical root swelling in the first $2.0 \mathrm{~mm}$ and several shoot and root growth parameters were measured in plants grown in a nutrient solution with and without $\mathrm{Fe}$, on different dates designated as days after transplantation (DAT). Correlations between the total chlorophyll concentration in young leaves and 22 morphological and physiological parameters were also calculated. The plants grown in the absence of Fe had a higher number of secondary roots at 3 DAT, compared to control plants. On the same date, subapical root swelling was also observed, particularly at 1.5 and $2.0 \mathrm{~mm}$ from the root tip. Those plants also had a lower chlorophyll content in young leaves and a higher ferric-chelate reductase activity (FCR; EC 1.16.1.17) in the roots. At 9 DAT, the overall vegetative performance (plant height, fresh weight of stems and leaves) was negatively affected. At the end of the experiment (14 DAT), significant correlations were found between chlorophyll and the studied parameters. In conclusion, tomato plants experienced a cascade of responses to Fe deficiency throughout nine days: firstly, root lateralization increased; later, root swelling was observed, and a decrease in leaf chlorophyll content was registered associated with an increase in root FCR. At the end, the biomass of tomato plants decreased.
\end{abstract}

Key words: chlorophyll, ferric-chelate reductase (FCR), plant nutrition, root lateralization, stress physiology, subapical root swelling

\begin{abstract}
Abbreviations:
Chl - chlorophyll, DAT - days after transplantation, DW - dry weight, FCR - ferric-chelate reductase, $\mathrm{Fe} 0$ - Fe deficient, Fe10 - Fe sufficient, FW - fresh weight, PPFD - photosynthetic photon flux density, R/S - roots/upper part of the tomato plants
\end{abstract}

\section{INTRODUCTION}

Understanding the mechanisms of $\mathrm{Fe}$ uptake, trafficking and homeostasis that occur both at the cellular level and whole plant level is essential to improve the quality and productivity of agricultural crops, and it contributes to healthier and improved

\footnotetext{
*Corresponding author. 
world food supplies. Since Fe is both essential and noxious to plant metabolism, the concentration and distribution of Fe to various organs and tissues must be tightly balanced within the physiological limits to provide the adequate amounts of $\mathrm{Fe}$ required for metabolic processes and plant survival (Guerinot and $\mathrm{Yi}, 1994)$. The regulation of $\mathrm{Fe}$ uptake is an initial process that is essential for maintaining $\mathrm{Fe}$ homeostasis in plants. In Fe-limiting conditions, higher plants have developed two strategies to facilitate $\mathrm{Fe}$ acquisition. These strategies were first described by Römheld and Marschner (1986) and are known as strategy I and strategy II. Strategy I (known as the reduction strategy) is based on the reduction of $\mathrm{Fe}$ (III) to $\mathrm{Fe}$ (II) before uptake via membrane-bound ferric-chelate reductase (FCR, belonging to the FRO (Ferric Reduction Oxidase) family of genes). This strategy is used by nongrass species such as Arabidopsis (Arabidopsis thaliana L. Heynh). The tomato plant (Solanum lycopersicum L.) is also broadly used as a model species for investigating this strategy (Zuchi et al., 2009; Paolacci et al., 2014).

The deprivation of $\mathrm{Fe}$ in plant tissues leads to a significantly reduced chlorophyll content in the leaves (Álvarez-Fernández et al., 2011). The characteristic yellow colour of chlorosis that occurs in young leaves is a result of a relative enrichment with carotenoids (Morales et al., 1990). Roots are also affected. Contrary to what happens under low $\mathrm{pH}(<5.0)$ conditions, which significantly decrease root growth (Graças et al., 2016), iron deficiency causes morphological modifications manifested as an increase in the number of secondary roots associated with root hair formation and root tip swelling, both of which aim to cover a greater area in the rhizosphere in the search for $\mathrm{Fe}$ (Pestana et al., 2012). Lateral root elongation is dependent on the auxin influx transporter (AUX1) that accumulates the growth substance auxin in newly formed lateral root tips (Giehl et al., 2012). In a study performed on Arabidopsis, the aha7 mutant showed significantly fewer root hairs, suggesting a contribution of AHA7 in the differentiation of rhizodermic cells (Santi and Schmidt, 2009). In Malus spp. grown in a root-split system, it was found that the Feinduced physiological responses were mediated by systematic auxin signalling from shoots to roots $(\mathrm{Wu}$ et al., 2012). Although some important work has been done to understand the physiological mechanisms involved in the response to iron deficiency, such as hormonal regulation (Landsberg, 1995) or ethylene participation (Romera and Alcántara, 2004; Lucena et al., 2015), external morphology traits such as subapical root swelling has not yet been quantified in any species. To our knowledge, it has only been qualitatively described in some crops such as orange and carob trees (Pestana et al., 2001; Correia et al., 2003). Understanding subapical root swelling may reveal the location and speed of the responses to $\mathrm{Fe}$ deprivation.

The aim of this research was to study with precision the temporal response of tomato plants to iron deficiency on different days after transplantation (DAT) by means of 22 quantitative parameters related to overall plant growth, root morphology and physiology, and chlorophyll content in the leaves.

\section{MATERIAL AND METHODS}

\section{Plant culture}

Plants of tomato (Solanum lycopersicum L.) cv. Roma presenting two fully expanded leaves and obtained from a commercial nursery were sterilised by immersion for $24 \mathrm{~h}$ in a solution with $1.33 \mathrm{~g} \mathrm{~L}^{-1}$ of fosetyl-aluminium and then washed thoroughly in running water.

The plants were placed in 20-L plastic containers filled with Hoagland's nutrient solution: $5 \mathrm{mM} \mathrm{Ca}\left(\mathrm{NO}_{3}\right)_{2}, 5 \mathrm{mM} \mathrm{KNO}, 1 \mathrm{mM} \mathrm{KH}_{2} \mathrm{PO}_{4}$, $2 \mathrm{mM} \mathrm{MgSO}{ }_{4}, 46 \mu \mathrm{M} \mathrm{H}_{3} \mathrm{BO}_{3}, 0.8 \mu \mathrm{M} \mathrm{ZnSO}_{4}$, $0.4 \mu \mathrm{M} \mathrm{CuSO}_{4}, 9 \mu \mathrm{M} \mathrm{MnCl}_{2}$, and $0.02 \mu \mathrm{M} \mathrm{MoO}_{3}$, containing either $10 \mu \mathrm{M} \mathrm{Fe}$ (Fe10, added as Fe(III)FeEDDHA, control plants) or no $\mathrm{Fe}(\mathrm{Fe} 0)$. The initial $\mathrm{pH}$ of the hydroponic medium was adjusted with $\mathrm{NaOH}(1 \mathrm{M})$ to $6.0 \pm 0.1$, and the electrical conductivity (EC, $2.2 \pm 0.1 \mathrm{dS} \mathrm{m}^{-1}$ ) was assessed daily. The solutions were constantly aerated using an air pump and a diffusion system. Plants were maintained in a glasshouse under natural photoperiod conditions: a photosynthetic photon flux density (PPFD) of $150-450 \mu \mathrm{mol} \mathrm{m}^{-2} \mathrm{~s}^{-1}$, and the temperature ranged between 20 and $25^{\circ} \mathrm{C}$, values that are normally registered in the Mediterranean region during spring.

The experimental layout was a randomized design with 6 plants per treatment ( $\mathrm{Fe} 0$ (Fedeficient) and Fe10 (Fe-sufficient)), with three replicates, and 4 sampling dates (3, 6, 9 and 14 days after transplantation (DAT)), with a total of 144 tomato plants (6 plants per container and a total of 24 containers). At the beginning of the experiment (0 DAT), a set of another fifteen (five per replicate) plants was used for general plant characterization. 
On each date, five plants from each treatment and replicate were separated into roots, stems, young leaves and mature leaves, and one plant was used to determine the volume of the whole root system $(\mathrm{mL})$.

\section{Assessment of total leaf chlorophyll concentration}

The total leaf chlorophyll (Chl) concentration per unit area $\left(\mu \mathrm{mol} \mathrm{m}^{-2}\right)$ was estimated nondestructively using a SPAD-502 Chlorophyll Meter (Minolta Camera Co., Osaka, Japan). A calibration curve had previously been established between SPAD values and Chl concentration by extracting pigments from leaves with different degrees of chlorosis, from the same area where SPAD readings had been taken. Pigment extraction was done with pure acetone in the presence of $\mathrm{Na}$ ascorbate (Abadía and Abadía, 1993), and the total leaf chlorophyll (Chl) concentration per unit area $\left(\mu \mathrm{mol} \mathrm{m} \mathrm{m}^{-2}\right.$ ) was measured spectrophotometrically. The Lichtenthaler (1987) equations were used to estimate Chl, and a general linear model:

$$
\left(\mathrm{y}=\mathrm{b}_{0}+\mathrm{b}_{1} \mathrm{x}\right)
$$

was fitted between SPAD values and total Chl concentration $\left(\mu \mathrm{mol} \mathrm{m}^{-2}\right)$ (Fig. 1).

SPAD readings were taken on one mature basal leaf and on one fully expanded new leaf (apical leaf) of six plants per treatment and replicate at least five times a week.

The evolution of the decrease in the total leaf chlorophyll concentration per unit area $(\Delta \mathrm{Chl}$, $\mu \mathrm{mol} \mathrm{m}{ }^{-2}$ ) between the $\mathrm{Fe}$ treatments (Fe-deficient $(\mathrm{Fe} 0)$ and Fe-sufficient (Fe10)) was calculated for each date using the following equation:

$$
\Delta \mathrm{Chl}=\mathrm{Chl}_{\mathrm{Fe} 0}-\mathrm{Chl}_{\mathrm{Fe} 10}
$$

\section{Evaluation of root swelling}

\section{Root system}

On each date, the whole root system of a plant was examined in each treatment and replicate. The volume of the entire root system $(\mathrm{mL})$ was determined from the volume of water displaced by immersing the roots in a test tube with a 100 $\mathrm{mL}$ capacity. Five roots of these plants per date, treatment and replicate were selected, and the degree of swelling was determined by classifying the roots into four categories according to a methodology previously established by our group: category 0 (no root swelling; S0), category 1 (root swelling in the first quarter of its length at the root tip; S1), category 2 (root swelling up to half its length; S2), and category 3 (more than half the root had swelled; S3). Additionally, in the same plants, the number of roots with secondary roots in the first $2.0 \mathrm{~cm}$ from the root tip was quantified to calculate root lateralization, defined as the percentage (\%) of roots with secondary roots in the first $2.0 \mathrm{~cm}$ of their length.

\section{Root segments}

Ten apical root segments (with a length of approximately $2.0 \mathrm{~cm}$ ) per date, treatment, and replicate were taken and maintained by immersion in distilled water to avoid dehydration. Then, the root tips were fixed in an FAE solution (formalin, acetic acid, 95\% ethanol and distilled water 10:5:50:35 $\mathrm{v} / \mathrm{v} / \mathrm{v} / \mathrm{v}$ ) according to Berlyn and Miksche (1976).

Photographic images of all the root segments were taken with a Nikon digital camera (Digital Sight DS-Ril) connected to a Nikon binocular loupe (SMZ 1270, Tokyo, Japan). Nis-Elements AR version 3.2 software was used to obtain the root

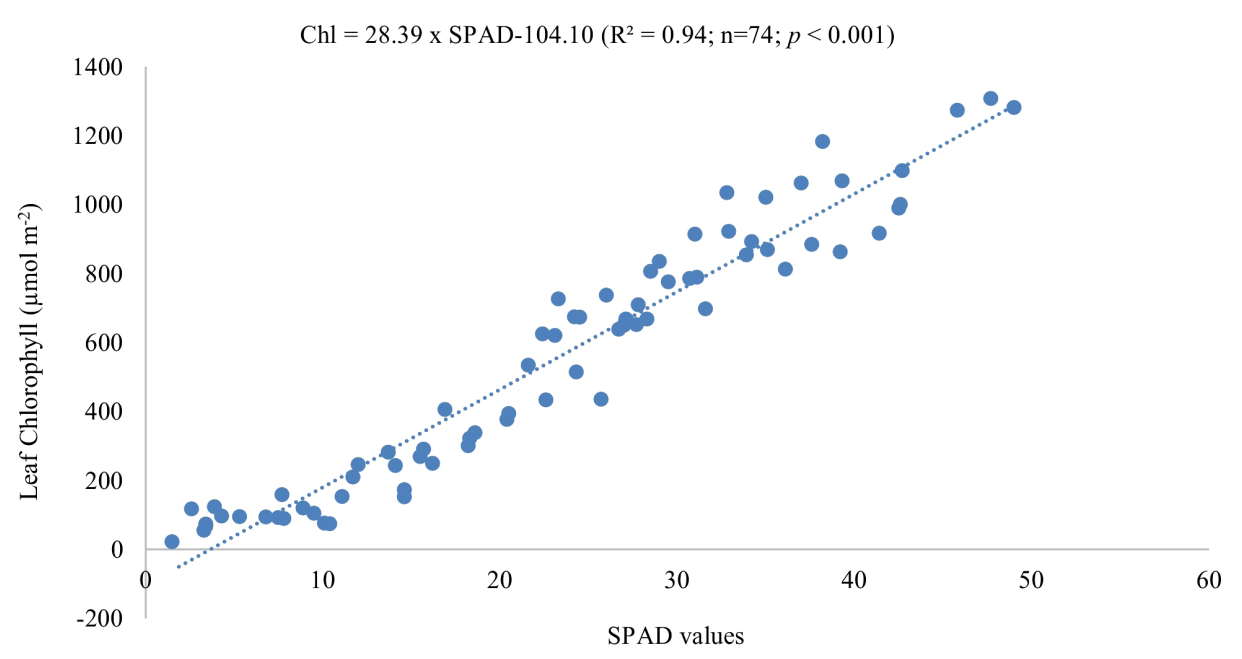

Figure 1. Calibration curve between SPAD values and total leaf Chl concentration $\left(\mu \mathrm{mol} \mathrm{m} \mathrm{m}^{-2}\right)$ in tomato plants 


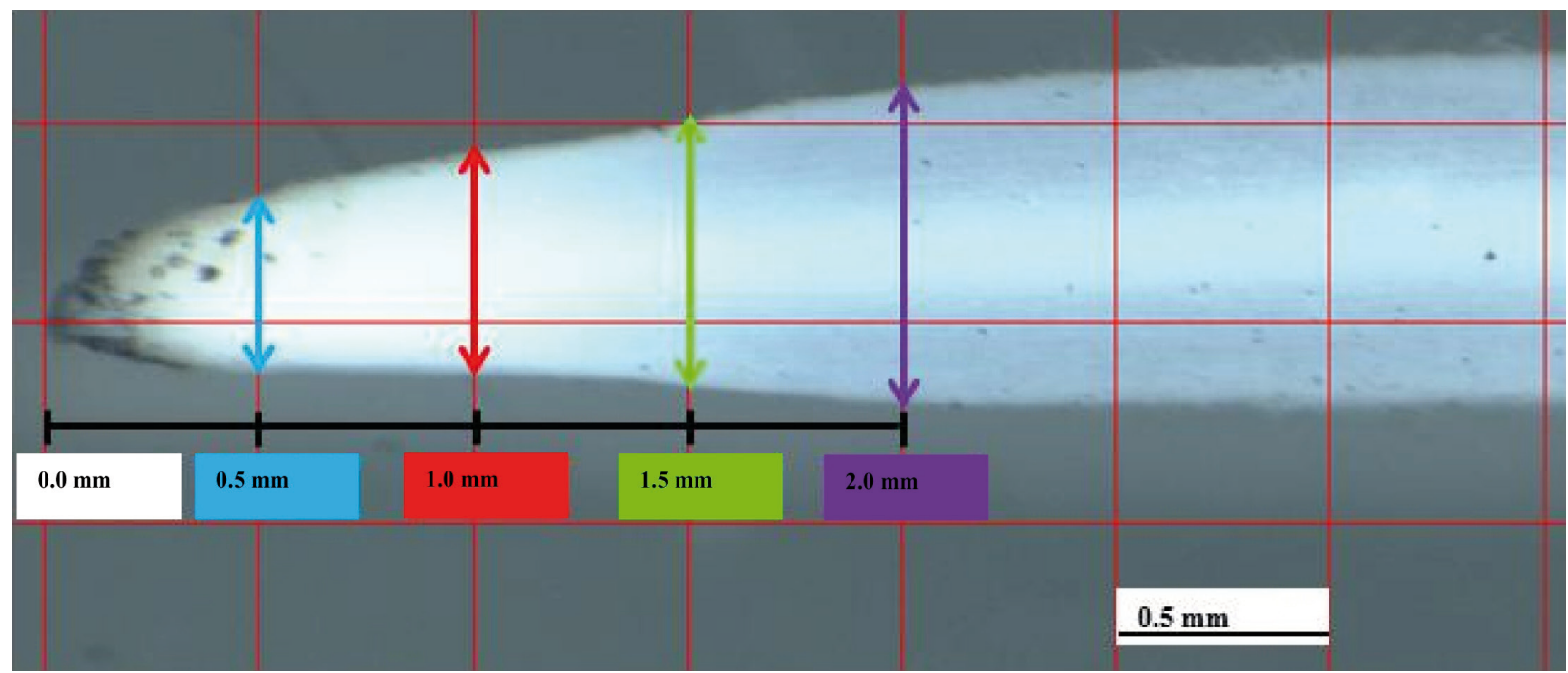

Figure 2. Square grid used to measure the root diameter at different distances $(0.5,1.0,1.5$, and $2.0 \mathrm{~mm})$ from the root tip

diameter measurements. Subapical root swelling was calculated as the difference between the diameter $(\mu \mathrm{m})$ of the $\mathrm{Fe} 0$-treatment (Fe-deficient) roots and the Fe10-treatment (Fe-sufficient) roots at different distances from the root tip: 0.5, 1.0, 1.5, and $2.0 \mathrm{~mm}$. A square grid $(0.5 \mathrm{~mm} \times 0.5 \mathrm{~mm})$ (Fig. 2) was used to measure the cross-distance using NISElements AR 3.2.

\section{Determination of Fe reduction}

The activity of ferric-chelate reductase (FCR; EC 1.16.1.17) was measured in a root tip in five plants per each date, treatment, and replicate, through the formation of a red $\mathrm{Fe}(\mathrm{II})-(\mathrm{BPDS})_{3}$ complex according to the methodology of Bienfait et al. (1983). A root tip (with a length of approximately 2.0 $\mathrm{cm}$ ) of each plant was incubated in the dark for one hour in an Eppendorf tube $(2 \mathrm{~mL})$ with $900 \mu \mathrm{L}$ of micronutrient-free half-strength Hoagland's nutrient solution containing $300 \mu \mathrm{M}$ BPDS, $500 \mu \mathrm{M}$ Fe(III)EDTA and $5 \mathrm{mM}$ MES buffer, at $\mathrm{pH}$ 6.0. Blank controls without plant material (extinction coefficient of $22.14 \mathrm{mM} \mathrm{cm}^{-1}$ ) were also used to correct for any unspecific Fe reduction. All readings of FCR activity (nmol Fe(II) $\min ^{-1} \mathrm{~g}^{-1}$ ) were calculated on the basis of the fresh weight $(\mathrm{FW}, \mathrm{g})$ of roots.

\section{Biomass}

On each date, five tomato plants per treatment and replicate were separated into roots, stem, mature leaves and young leaves. The samples were washed with a non-ionic detergent $(0.1 \%)$ to remove surface contamination, then washed with tap water, and finally rinsed three times with deionised water. The fresh weight $(\mathrm{FW}, \mathrm{g})$ was determined for each collected sample, and the dry weight (DW, g) was estimated after drying at $60^{\circ} \mathrm{C}$ for at least $48 \mathrm{~h}$ until the samples had reached a constant weight.

\section{Statistical analysis}

An analysis of variance (ANOVA, F test) and Duncan's Multiple Range Test (DMRT) at $p<0.05$ (IBM SPSS ${ }^{\circledR}$ software version 20 ) were used to discriminate significant differences among the mean values. Pearson's correlation coefficients $(r)$ between the total leaf chlorophyll (Chl) concentration per unit area $\left(\mu \mathrm{mol} \mathrm{m}{ }^{-2}\right)$ of young leaves (dependent variable) and each of the 22 morphological and physiological parameters were also determined.

\section{RESULTS}

\section{Effect of iron deficiency in leaves}

Typical interveinal chlorosis of young leaves started at 6 DAT and became increasingly pronounced until the end of the experiment (14 DAT), while the control plants remained green.

From 6 DAT, the SPAD values in young leaves were significantly different between the treatments (Tab. 1). However, in mature leaves, significant differences were observed only after day 7 .

Figure 3 shows the evolution of the decrease in the total leaf chlorophyll concentration per unit area $\left(\Delta \mathrm{Chl}, \mu \mathrm{mol} \mathrm{m} \mathrm{m}^{-2}\right)$ during the experiment, where each point represents the difference between the chlorophyll values of the $\mathrm{Fe} 0$ and Fel0 treatments. After transplantation, the decrease in chlorophyll was more marked in young leaves than in mature leaves, and it was significant starting from 7 DAT. As expected, at the end of the experiment, the 
Table 1. Mean values of SPAD in young and mature tomato leaves according to the Fe level $(n=18)$

\begin{tabular}{lcccc}
\hline & \multicolumn{2}{c}{ Young leaves } & \multicolumn{2}{c}{ Mature leaves } \\
\cline { 2 - 5 } *DAT & $\begin{array}{c}\text { Fe-sufficient } \\
\text { (Fe10) }\end{array}$ & $\begin{array}{c}\text { Fe-deficient } \\
(\text { Fe0) }\end{array}$ & $\begin{array}{c}\text { Fe-sufficient } \\
(\text { Fe10) }\end{array}$ & $\begin{array}{c}\text { Fe-deficient } \\
(\text { Fe0) }\end{array}$ \\
\hline 0 & $34.75 \mathrm{a}$ & $34.75 \mathrm{a}$ & $36.19 \mathrm{a}$ & $36.19 \mathrm{a}$ \\
1 & $37.49 \mathrm{a}$ & $37.70 \mathrm{a}$ & $37.09 \mathrm{a}$ & $37.66 \mathrm{a}$ \\
2 & $40.73 \mathrm{a}$ & $40.40 \mathrm{a}$ & $38.93 \mathrm{a}$ & $38.81 \mathrm{a}$ \\
3 & $41.13 \mathrm{a}$ & $41.46 \mathrm{a}$ & $36.52 \mathrm{a}$ & $36.95 \mathrm{a}$ \\
6 & $42.06 \mathrm{~b}$ & $37.21 \mathrm{a}$ & $38.76 \mathrm{a}$ & $37.06 \mathrm{a}$ \\
7 & $41.08 \mathrm{~b}$ & $28.34 \mathrm{a}$ & $39.80 \mathrm{~b}$ & $35.89 \mathrm{a}$ \\
8 & $39.91 \mathrm{~b}$ & $24.62 \mathrm{a} *$ & $38.96 \mathrm{~b}$ & $35.67 \mathrm{a}$ \\
9 & $36.64 \mathrm{~b}$ & $16.59 \mathrm{a}$ & $41.45 \mathrm{~b}$ & $35.74 \mathrm{a}$ \\
10 & $41.35 \mathrm{~b}$ & $14.78 \mathrm{a}$ & $43.78 \mathrm{~b}$ & $35.97 \mathrm{a}$ \\
12 & $36.86 \mathrm{~b}$ & $10.86 \mathrm{a}$ & $42.28 \mathrm{~b}$ & $34.23 \mathrm{a}$ \\
14 & $35.89 \mathrm{~b}$ & $11.72 \mathrm{a}$ & $42.23 \mathrm{~b}$ & $31.99 \mathrm{a}$ \\
\hline
\end{tabular}

*DAT: days after transplantation

Mean values followed by different lower-case letters $(a, b)$ in the same row indicate significant differences for each Fe treatment for young and mature leaves. The asterisk $(*)$ indicates the date on which differences between the treatments were visually observed

extent of iron chlorosis was greater in young leaves $\left(\Delta \mathrm{Chl}=-858.35 \mu \mathrm{mol} \mathrm{m}^{-2}\right)$ than in mature leaves $\left(\Delta \mathrm{Chl}=-394.67 \mu \mathrm{mol} \mathrm{m}^{-2}\right)$.

\section{Effect of iron deficiency on roots}

The plants grown without $\mathrm{Fe}$ presented root hairs and a subapical root swelling, compared to the Fe10 (Fe-sufficient) plants, which did not show such alteration (Fig. 4A). Secondary roots were also observed on the roots of chlorotic plants, with more found in the $\mathrm{Fe} 0$ treatment than in the $\mathrm{Fe} 10$ treatment.

With respect to the classification according to the degree of root swelling, the root system of the tomato plants grown with Fe (control plants, Fe10) was classified as category $0(\mathrm{~S} 0)$, regardless of the date. At 3 DAT, $63.3 \%$ of the roots in the $\mathrm{Fe} 0$ treatment did not display any swelling (category 0 ), and $36.7 \%$ of the roots presented a swelling classified as category 1 . At 6 DAT, $90.0 \%$ of the roots presented a swelling classified as category 1 (S1), 6.7\% were classified as category 2 (S2), and only 3.3\% did not show any swelling (category $0 ; \mathrm{S} 0$ ). On the last date, at 14 DAT, the entire root system showed signs of swelling: $56.7 \%$ of the roots presented a swelling classified as category 1 (S1), 33.3\% as category 2 (S2) and $10.0 \%$ as category $3(\mathrm{~S} 3)$.

The root diameters $(\mu \mathrm{m})$ at different distances $(0.5,1.0,1.5$ and $2.0 \mathrm{~mm})$ from the root tip, for each treatment and at $0,3,6,9$ and 14 DAT, are shown in Table 2. Significant differences in root diameter, higher in $\mathrm{Fe}$-deficient $(\mathrm{Fe} 0)$ with respect to Fe-sufficient (Fe10), were observed between the treatments after 6 DAT for all the distances (439.39 and $334.49 \mu \mathrm{m}$ for $0.5 \mathrm{~mm} ; 559.31$ and $387.36 \mu \mathrm{m}$ for $1 \mathrm{~mm} ; 715.80$ and $398.50 \mu \mathrm{m}$ for $1.5 \mathrm{~mm} ; 799.04$ and $406.18 \mu \mathrm{m}$ for $2.0 \mathrm{~mm}$, respectively).

In the absence of $\mathrm{Fe}$ ( $\mathrm{Fe} 0$ treatment), the root diameter increased 2-4 times at all the distances $(0.5,1.0,1.5$ and $2.0 \mathrm{~mm})$ from the beginning of the

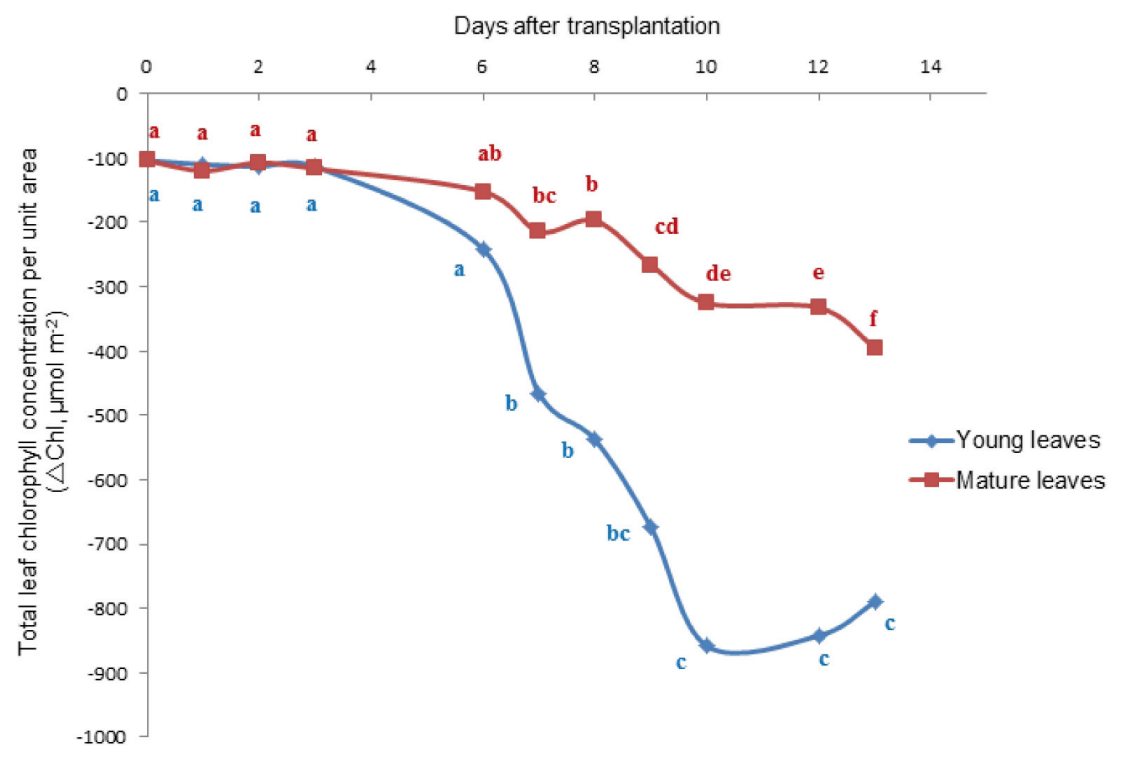

Figure 3. Evolution of the decrease in the total leaf chlorophyll concentration per unit area $\left(\Delta \mathrm{Chl}, \mu \mathrm{mol} \mathrm{m}^{-2}\right)$ during the experiment, where each point represents the difference between the chlorophyll values of the $\mathrm{Fe} 0$ and Fe 10 treatments. Different lower-case letters at each curve indicate significant differences between DAT for young and mature leaves $(p<0.05)(\mathrm{n}=18)$ 
A
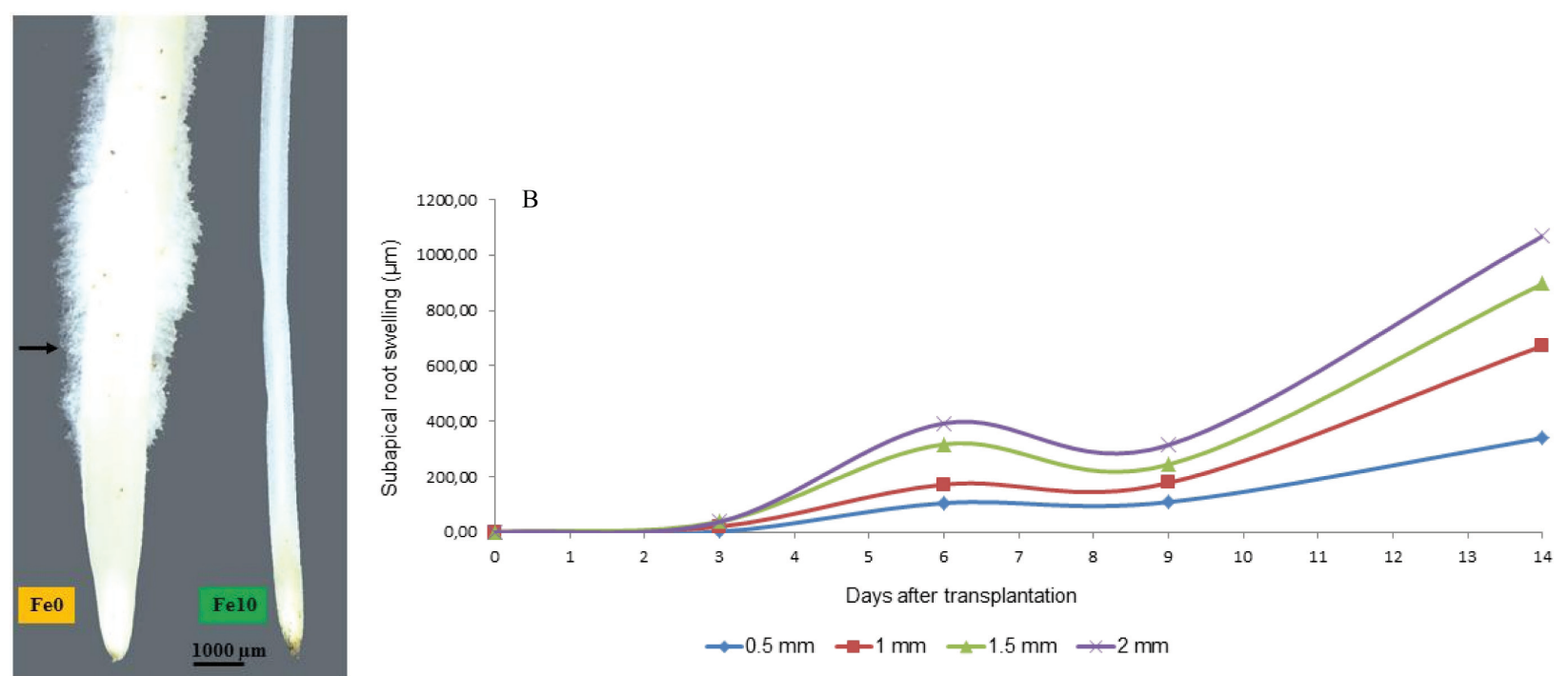

Figure 4. Root segments observed under a Nikon binocular microscope, with a subapical root swelling in the Fedeficient $(\mathrm{Fe} 0)$ treatment and no such alteration in the Fe-sufficient (Fe10) treatment. $\longrightarrow$ indicates the formation of root hairs (Fig. 4A). Progress of subapical root swelling (diameter $\mathrm{Fe} 0(\mu \mathrm{m})$ - diameter Fe10 $(\mu \mathrm{m})$ ) after transplantation measured at different distances from the root tip $(n=30)$ (Fig. 4B)

experiment until 14 DAT. In the Fe10 treatment, the root diameter also increased, although to a lesser extent (1.2-1.5 times), after 9 DAT, and the increase was significant at the distances of $0.5,1.0$ and 1.5 $\mathrm{mm}$ (Tab. 2).

Subapical root swelling was calculated as the difference between the diameter $(\mu \mathrm{m})$ of the $\mathrm{Fe} 0$ roots and that of the Fe10 roots for each date. After that difference had been plotted against DAT (Fig. $4 \mathrm{~B})$, pronounced root swelling was observed in the $1.5-2.0 \mathrm{~mm}$ segment, particularly from 6 DAT onwards. However, as iron deficiency develops over time, root swelling eventually occurred at all the set distances.

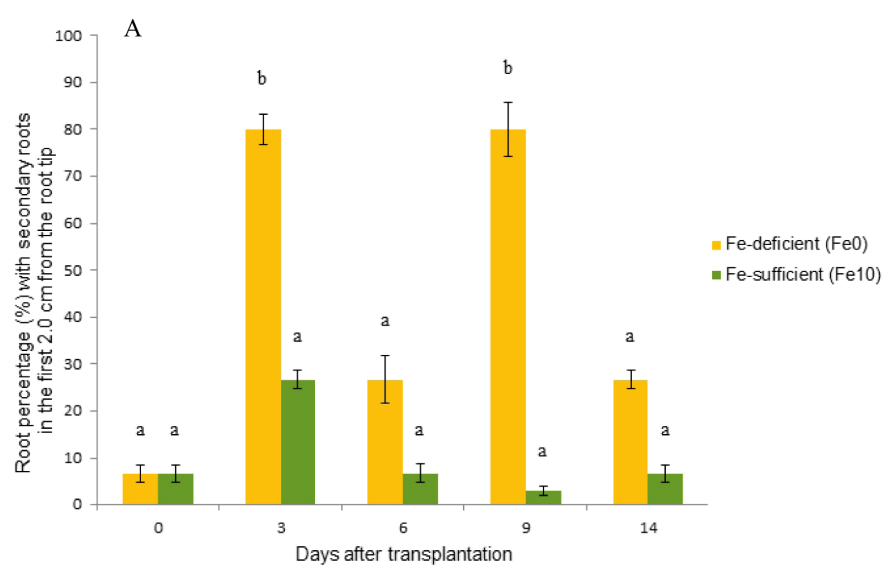

Root lateralization (percentage (\%) of roots with secondary roots in the first $2.0 \mathrm{~cm}$ from the root tip) significantly increased in $\mathrm{Fe} 0$ (Fe-deficient) plants compared with Fe10 (Fe-sufficient) plants at 3 DAT ( $80 \%$ and $26.70 \%$, respectively) and 9 DAT $(80 \%$ and $3.0 \%$, respectively) (Fig. 5A).

The ferric-chelate reductase (FCR) activity (nmol Fe(II) $\min ^{-1} \mathrm{~g}^{-1} \mathrm{FW}$ ) increased significantly in the roots of plants grown under Fe-deficiency compared to control plants from 6 DAT (8.90 and $2.30 \mathrm{nmol} \mathrm{Fe}(\mathrm{II})$ min-1 g-1 FW, respectively) until the end of the study (14 DAT; 17.60 and $2.70 \mathrm{nmol}$ $\mathrm{Fe}(\mathrm{II}) \mathrm{min}^{-1} \mathrm{~g}^{-1} \mathrm{FW}$, respectively) (Fig. 5B).

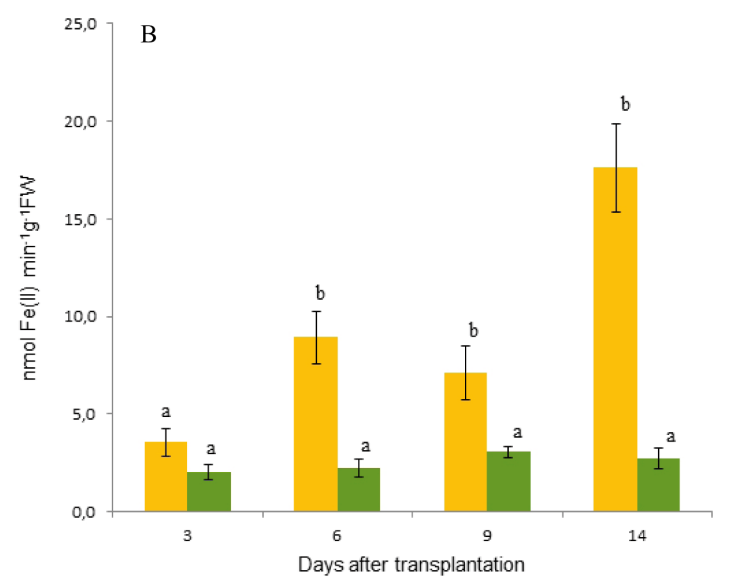

Figure 5. Root lateralization (percentage (\%) of roots with secondary roots in the first $2.0 \mathrm{~cm}$ from the root tip; $\mathrm{n}=15$; Fig. 5A) and root ferric-chelate reductase (FCR) activity (nmol Fe(II) $\min ^{-1} \mathrm{~g}^{-1} \mathrm{FW}$ measured on different days after transplantation; $\mathrm{n}=15$; Fig. 5B). Different lower-case letters $(\mathrm{a}, \mathrm{b})$ indicate significant differences for each Fe treatment and days after transplantation $(p<0.05)$. Vertical bars represent \pm SD 


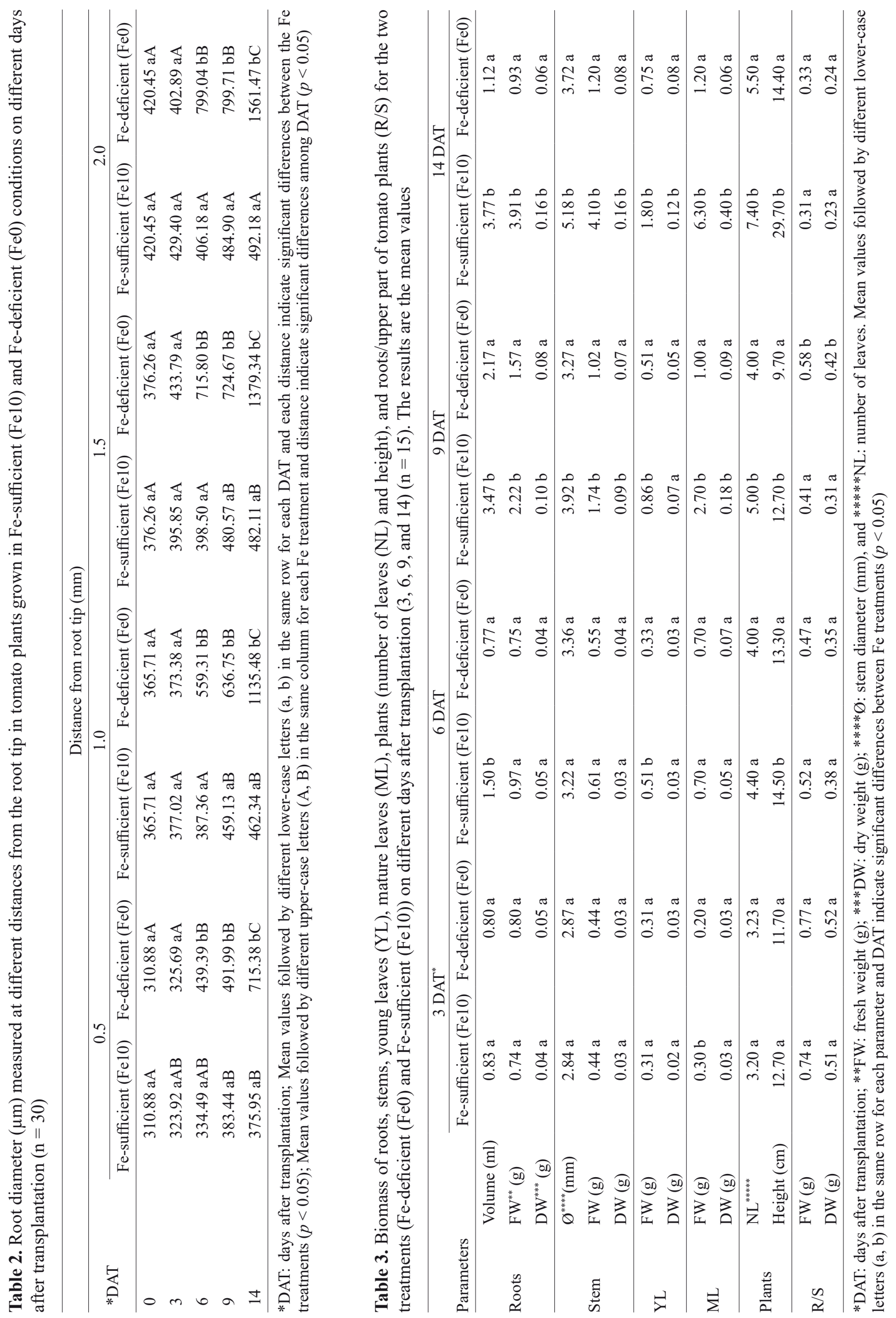




\section{Effect of iron deficiency on biomass}

The fresh weight (FW) of mature leaves was significantly different between the Fe treatments three days after transplantation (3 DAT; Tab. 3). Six days after transplantation (6 DAT), significant differences were observed in the volume of roots $(\mathrm{mL})$, FW of young leaves, and plant height. At 9 DAT, significant differences between the treatments were found for all the parameters except the dry weight (DW) of young leaves. At the end of the study (14 DAT), significant differences between the treatments were also found for all the parameters studied, except the roots/upper part of the tomato plants (R/S) (FW and DW). In all the parameters for which the difference exhibited statistical significance, the values obtained in the $\mathrm{Fe} 0$ treatment were significantly lower than those in Fe10, except for the parameter R/S at 9 DAT.

\section{Relationship between total chlorophyll concentration in young leaves and several parameters}

Pearson's correlation coefficients $(r)$ for the total leaf chlorophyll (Chl) concentration per unit area $\left(\mu \mathrm{mol} \mathrm{m}{ }^{-2}\right)$ of young leaves versus each of the 22 morphological and physiological parameters at different DAT were calculated. Table 4 shows only the significant correlations, which are presented in a descending order. The total chlorophyll concentration in young leaves was strongly correlated with the vegetative parameters (e.g., height, fresh weight of mature leaves and stems (FW)) determined at the end of the experiment (9 and 14 DAT), when severe chlorosis was evident. On those dates, lower Chl was also related to greater swelling, which is expressed by the negative sign of $r$. Three days after transplantation (latent chlorosis), the Chl of young leaves was positively correlated with FW $(r=0.58)$ and Chl $(r=0.49)$ of mature leaves. The activity of FCR in the roots (nmol Fe(II) $\min ^{-1} \mathrm{~g}^{-1} \mathrm{FW}$ ) was strongly correlated at the end of the experiment (14 DAT). Surprisingly, at 6 DAT, no significant correlations were found.

\section{DISCUSSION}

The effect of Fe deficiency on root morphological traits is well documented in several species (Schmidt, 1999; Hindt and Guerinot, 2012). These changes include root swelling, the formation of new root tips and root hairs, and the formation of transfer cells (e.g. Pestana et al., 2004). However, it remains an open question whether those alterations are directly coupled with physiological responses (von Wirén and Bennett, 2016) and how fast they occur, suggesting that some specific pathways involved in $\mathrm{Fe}$ stress response are poorly known.

In young maize seedlings subjected to nutritional deficiencies, Li et al. (2015) concluded that root hairs might sense the external lack of a specific nutrient and adjust their metabolism accordingly. In general, it has been reported that alterations in root morphology start before visible leaf chlorosis symptoms. In sugar beet, latent Fe deficiency induces subapical swelling with root hairs and the formation of transfer cells (Landsberg, 1995). In Fe-efficient potato genotypes (a strategy I species), root hairs and the formation of lateral roots were enhanced if the plants were grown under $\mathrm{Fe}$ deficiency conditions. At the physiological level, there was an increased expression of ferritin in the leaves and of an iron-regulated transporter (irt1) in the roots (Boamponsem et al., 2017). Kawahara and Kitamura (2015) reported that the swelling of root tips in Hyoscyamus albus L. (Solanaceae) subjected to Fe depletion was related to changes in both cell size and number, and to the development of root hairs.

In our work, 3 days after Fe depletion (3 DAT), no chlorosis symptoms were developed in the aerial plant parts (Tab. 1). The chlorophyll concentrations in the leaves (young and mature) (Fig. 3) and several biomass parameters were not affected during this early stage of $\mathrm{Fe}$ stress (Tab. 3). However, root modifications began at this stage, which was supported by the high number of secondary roots in Fe-deficient plants (Fig. 5A).

We may assume that an initial stress signal produced during root differentiation (at 3 DAT) was involved, and may subsequently trigger morphological and physiological response mechanisms to Fe deficiency. Therefore, in tomato plants, the period between 3 and 6 DAT seems to be critical to $\mathrm{Fe}$ stress response, and it is possible that an Fe-stress signal might be involved. Kobayashi and Nishizawa (2014) reviewed the nature of Festress signals and proposed several molecules as candidates: the iron itself, other metals, oxygen, the redox status, or haem and iron-sulphur clusters.

Auxins play a significant role in the response of root morphology to Fe deficiency, by altering root architecture (Giehl et al., 2012; Hindt and Guerinot, 2012), but other compounds such as nicotianamine or nitric oxide (NO) may also be important in $\mathrm{Fe}$ long-distance transport and Fe homeostasis. In fact, a higher NO level in Fe-deficient roots enhanced 
Table 4. Pearson's correlation coefficients $(r)$ between the calculated values of total chlorophyll concentration in young leaves (dependent variable) and several plant parameters on different dates throughout the experiment. Iron treatments were analysed as one $(n=176)$. Only the significant $(0.0001<p<0.05)$ correlations are shown. Negative slopes (inverse relations) are shown at the bottom

\begin{tabular}{|c|c|c|c|}
\hline & DAT $^{*}$ & $r$ & Significance \\
\hline Plant height (mm) & 14 & 0.87 & $* * * *$ \\
\hline Mature leaves - fresh weight (g) & 14 & 0.83 & $* * * *$ \\
\hline Stem fresh weight $(\mathrm{g})$ & 14 & 0.79 & $* * * *$ \\
\hline Mature leaves - fresh weight (FW, g) & 9 & 0.76 & $* * * *$ \\
\hline Roots - FCR activity (nmol Fe(II) $\min ^{-1} \mathrm{~g}^{-1} \mathrm{FW}$ ) & 14 & 0.75 & $* * * *$ \\
\hline Mature leaves - dry weight (g) & 9 & 0.73 & $* * * *$ \\
\hline Mature leaves - chlorophyll $\left(\mu \mathrm{mol} \mathrm{m} \mathrm{m}^{-2}\right)$ & 14 & 0.73 & $* * * *$ \\
\hline Mature leaves - dry weight (g) & 14 & 0.72 & $* * * *$ \\
\hline Stem diameter $(\mathrm{mm})$ & 14 & 0.72 & $* * * *$ \\
\hline Total root volume $(\mathrm{mL})$ & 14 & 0.71 & $* * * *$ \\
\hline Number of leaves & 14 & 0.69 & $* * * *$ \\
\hline Plant height (mm) & 9 & 0.66 & $* * * *$ \\
\hline Young leaves - fresh weight (g) & 14 & 0.66 & $* * * *$ \\
\hline Number of leaves & 9 & 0.64 & $* * *$ \\
\hline Roots - fresh weight (g) & 14 & 0.61 & $* * *$ \\
\hline Stem dry weight (g) & 14 & 0.60 & $* * *$ \\
\hline Stem fresh weight $(\mathrm{g})$ & 9 & 0.59 & $* *$ \\
\hline Mature leaves - fresh weight (g) & 3 & 0.58 & $* *$ \\
\hline Young leaves - dry weight (g) & 14 & 0.57 & $* *$ \\
\hline Young leaves - fresh weight (g) & 9 & 0.54 & $* *$ \\
\hline Mature leaves - chlorophyll $\left(\mu \mathrm{mol} \mathrm{m} \mathrm{m}^{-2}\right)$ & 9 & 0.53 & $* *$ \\
\hline Young leaves - dry weight (g) & 9 & 0.51 & $* *$ \\
\hline Mature leaves - chlorophyll $\left(\mu \mathrm{mol} \mathrm{m}{ }^{-2}\right)$ & 3 & 0.49 & $*$ \\
\hline Roots - FCR activity (nmol Fe(II) $\min ^{-1} \mathrm{~g}^{-1} \mathrm{FW}$ ) & 9 & 0.49 & $* *$ \\
\hline Young leaves - fresh weight (g) & 3 & 0.47 & * \\
\hline Roots - dry weight (g) & 3 & 0.43 & * \\
\hline Stem diameter $(\mathrm{mm})$ & 9 & 0.43 & * \\
\hline Total root volume $(\mathrm{mL})$ & 9 & 0.41 & * \\
\hline Roots - fresh weight $(\mathrm{g})$ & 9 & 0.39 & * \\
\hline Stem dry weight (g) & 9 & 0.38 & * \\
\hline Roots - dry weight (g) & 9 & -0.41 & * \\
\hline Subapical swelling of roots at $0.5 \mathrm{~mm}$ & 9 & -0.54 & $* *$ \\
\hline Secondary roots in the first $2.0 \mathrm{~cm}$ from the root tip & 9 & -0.61 & $* * *$ \\
\hline Roots - dry weight (g) & 14 & -0.62 & $* * *$ \\
\hline Subapical swelling of roots at $1.0 \mathrm{~mm}$ & 9 & -0.66 & $* * * *$ \\
\hline Subapical swelling of roots at $1.5 \mathrm{~mm}$ & 9 & -0.72 & $* * * *$ \\
\hline Subapical swelling of roots at $2.0 \mathrm{~mm}$ & 9 & -0.72 & $* * * *$ \\
\hline Subapical swelling of roots at $0.5 \mathrm{~mm}$ & 14 & -0.74 & $* * * *$ \\
\hline Subapical swelling of roots at $1.0 \mathrm{~mm}$ & 14 & -0.78 & $* * * *$ \\
\hline Subapical swelling of roots at $1.5 \mathrm{~mm}$ & 14 & -0.79 & $* * * *$ \\
\hline Subapical swelling of roots at $2.0 \mathrm{~mm}$ & 14 & -0.80 & $* * * *$ \\
\hline
\end{tabular}

${ }^{*}$ DAT: days after transplantation. Significance: $* p<0.05 ; * * p<0.01 ; * * * p<0.001$, and $* * * * p<0.0001$ 
root branching in tomato (Jin et al., 2011). In rice, for example, changes in root growth and morphological adaptations to $\mathrm{Fe}$ deficiency are regulated by a complex interaction between NO and IAA auxin (Sun et al., 2017).

The root tissue modifications in Fe-deficient plants were probably more common in the segment between 1.5 and $2.0 \mathrm{~mm}$ from the tip (Fig. 4B), as evidenced by the increase in root swelling at these distances. This is similar to the findings of Dasgan et al. (2002) in a 1-cm diameter transverse root section of several tomato genotypes. But how fast is the response of the aerial plant parts? Young developing leaves are a good indicator of $\mathrm{Fe}$ chlorosis (Morales et al., 1990), but it is interesting to decode the temporal cascade of events. Moreover, these morphological modifications at this specific location (root tips) were closely coupled to young leaf metabolism. After 9 DAT, the overall vegetative performance (expressed as plant height, fresh weight (FW, g) of stems and leaves) was negatively affected by Fe stress (expressed by the positive linear relations with Chl) (Tab. 4). Interestingly, the dry weight of roots at 9 and 14 DAT, was inversely correlated with the total chlorophyll concentration in young leaves, which may be attributed to the increase in secondary roots in Fe-deficient plants (Tab. 4). As expected, chlorosis of young leaves at 9 and 14 DAT was inversely related to root swelling at different distances from the tip.

Tomato plants followed a reduction strategy (strategy I) that relies on the reduction of $\mathrm{Fe}$ (III) to $\mathrm{Fe}$ (II) by a ferric-chelate reductase (FCR) enzyme located in the roots. The higher number of secondary roots in Fe-deficient plants may be an opportunity to increase Fe reduction points. However, the presence of root hairs in barley grown under Fe deficiency did not lead to a positive effect on growth or on $\mathrm{Fe}$ uptake compared to a root-hairless mutant brb (bald root barley) (Zuchi et al., 2011). The increment in the activity of this enzyme observed in Fe-deficient plants has been reported in numerous horticultural crops. In this study, root FCR activity (nmol Fe(II) $\mathrm{min}^{-1} \mathrm{~g}^{-1} \mathrm{FW}$ ) was significantly incremented after 6 days in Fe-deficient plants, and the differences between the treatments were greater thereafter (at 9 and 14 DAT) (Fig. 5B).

\section{CONCLUSIONS}

To decode the temporal response to iron deficiency in tomato plants, subapical root swelling and root morphological changes (secondary roots) have been precisely quantified on different days after transplantation, and the leaf chlorophyll concentration has been related to 22 morphological and physiological parameters. Our results indicate that as a response to Fe deficiency, a cascade of events starts with root lateralization (3 DAT), followed by root swelling (6 DAT) and an increase in FCR activity (6 DAT). Nine days after transplantation $(9$ DAT), tomato plant biomass is reduced due to this nutritional stress.

\section{ACKNOWLEDGEMENTS}

The authors wish to thank their colleague Dr. Hava. F. Rapoport from the Instituto de Agricultura Sostenible-CSIC (Spain) for her useful suggestions to define the root measurements and to Alejandro Jiménez for his help in the laboratory. The authors also express their gratitude to Dr. Fernando Martínez and Dr. Pilar Rallo, both from the Dpto. Ciencias Agroforestales, Universidad de Sevilla for critically revising this manuscript.

\section{FUNDING}

This study has been done with the help granted to M.R. Jiménez from the 5th Research Program of the University of Seville and the grant SFRH/ BD/89521/2012 from FCT (Portugal) granted to F. Gama.

\section{AUTHOR CONTRIBUTIONS}

M.R.J., M.P., P.J.C., T.S., F.G., and L.C. - conceived and designed the experiments; T.S., F.G., M.R.J., and L.C. - executed the experiments, analysed the data and prepared the manuscript; M.R.J., L.C., P.J.C., M.P., and M.P.S. - wrote the manuscript. All the authors contributed to the discussion of the results, and all of them read and approved the final manuscript.

\section{CONFLICT OF INTEREST}

The author declares no conflict of interest.

\section{REFERENCES}

ABAdíA J., ABADÍA A., 1993. Iron and pigments. In: Iron Chelation in Plants and Soil Microorganisms. L.L. Barton and B.C. Hemming (Eds), Academic Press, San Diego, USA, 327-343.

Álvarez-Fernández A., Melgar J.C, Abadía J., ABADía A., 2011. Effects of moderate and severe iron deficiency chlorosis on fruit yield, appearance and composition in pear (Pyrus communis L.) and peach (Prunus persica (L.) Batsch). Environ. Exper. Bot. 71, 280-286. 
Berlyn G.P., Miksche J.P., 1976. Botanical Microtechnique and Cytochemistry. Ames Iowa: Iowa State University Press, USA.

Bienfait H.F., Bino R.J., VAN DER Blick A.M., Duivenvoorden J.F., Fontaine J.M., 1983. Characterization of ferric reducing activity in roots of Fe-deficient Phaseolus vulgaris. Physiol. Plant. 59, 196-202.

BoAmponsem G.A., Leung D.W.M., Lister C., 2017. Insights into resistance to Fe deficiency stress from a comparative study of in vitro-selected novel Feefficient and Fe-inefficient potato plants. Front. Plant Sci. 8, 1581.

Correia P.J., Pestana M., Martins-LouÇão M.A., 2003. Nutrient deficiencies in carob (Ceratonia siliqua L.) grown in solution culture. J. Hortic. Sci. Biotechnol. 78, 847-852.

Dasgan H.Y., Römheld V., Cakmak I., AbaK K., 2002. Physiological root responses of iron deficiency susceptible and tolerant tomato genotypes and their reciprocal $F_{1}$ hybrids. Plant Soil 241, 97-104.

GIEHL R.F.H., LIMA J.E., vON WIRÉN N., 2012. Localized iron supply triggers lateral root elongation in Arabidopsis by altering the AUX1-mediated auxin distribution. Plant Cell 24, 33-49.

Graças J.P., Ruiz-Romero R., Figueiredo L.D., Mattiello L., Peres, L.E.P., Vitorello V.A., 2016. Root growth restraint can be an acclimatory response to low $\mathrm{pH}$ and is associated with reduced cell mortality: a possible role of class III peroxidases and NADPH oxidases. Plant Biol. 18, 658-668.

Guerinot M.L., Yi Y., 1994. Iron: nutritious, noxious, and not readily available. Plant Physiol. 104, 815820.

Hindt M.N., Guerinot M.L., 2012. Getting a sense for signals: regulation of the plant iron deficiency response. Biochim. Biophys. Acta 1823, 1521-1530.

Jin C.W., Du S.T., Shamsi I.H., Luo B.F., Lin X.Y., 2011. NO synthase-generated NO acts downstream of auxin in regulating Fe-deficiency-induced root branching that enhances Fe-deficiency tolerance in tomato plants. J. Exp. Bot. 62, 3875-3884.

Kawahara Y., Kitamura Y., 2015. Changes in cell size and number and in rhizodermal development contribute to root tip swelling of Hyoscyamus albus roots subjected to iron deficiency. Plant Physiol. Biochem. 89, 107-111

Kobayashi T., NishizaWa N.K., 2014. Iron sensors and signals in response to iron deficiency. Plant Sci. 224, 36-43.

LANDSBERG E-C., 1995. Transfer cells formation in sugar beet roots induced by latent Fe deficiency. In: Iron Nutrition in Soils and Plants. J. Abadía. (Ed.), Springer, Dordrecht, Netherlands, 67-75.

Li Z., Phillip D., Neuhäuser B., Schulze W.X., LUDEWIG U., 2015. Protein dynamics in young maize root hairs in response to macro and micronutrient deprivation. J. Proteome Res. 14, 3362-3371.
LiCHTENTHALER H.K., 1987. Chlorophylls and carotenoids: pigments of photosynthetic biomembranes. Methods Enzymol. 148, 350-382.

Lucena C., Romera F.J., García M.J., Alcántara E., PÉREZ-VICENTE R., 2015. Ethylene participates in the regulation of Fe deficiency responses in strategy I plants and in rice. Front. Plant Sci. 6, 1-16.

Morales F., AbAdíA A., ABADÍA J., 1990. Characterization of the xanthophyll cycle and other photosynthetic pigment changes induced by iron deficiency in sugar beet (Beta vulgaris L.). Plant Physiol. 94, 607613.

Paolacci A.R., Celletti S., Catarcione G., Hawkesford M.J., Astolfi S., CiafFi M., 2014. Iron deprivation results in a rapid but not sustained increase of the expression of genes involved in iron metabolism and sulfate uptake in tomato (Solanum lycopersicum L.) seedlings. J. Int. Plant Biol. 56, 88100.

Pestana M., Correia P.J., SaAvedra T., Gama F., Abadía A., DE VArennes A., 2012. Development and recovery of iron deficiency by iron resupply to roots or leaves of strawberry plants. Plant Physiol. Biochem. 53, 1-5.

Pestana M., David M., de Varennes A., Abadía J., FARIA E.A., 2001. Responses of 'Newhall' orange trees to iron deficiency in hydroponics: effects on leaf chlorophyll, photosynthetic efficiency and root ferric chelate reductase activity. J. Plant Nutr. 24, 1609-1620.

Pestana M., Faria E.A., De Varennes A., 2004. Limeinduced iron chlorosis in fruit trees. In: Production Practices and Quality Assessment of Food Crops. R. Dris and S.M. Jain (Eds), Springer, Dordrecht, Netherlands, 171-215.

Romera F.J., AlCÁNTARA E., 2004. Ethylene involvement in the regulation of Fe-deficiency stress responses by Strategy I plants. Funct. Plant Biol. 31, 315-328.

RöMHeld V., MARSCHNER H., 1986. Mobilization of iron in the rhizosphere of different plant species. Adv. Plant Nutr. 2, 155-204.

SAnti S., Schmidt W., 2009. Dissecting iron deficiencyinduced proton extrusion in Arabidopsis roots. New Phytol. 183, 1072-1084.

SCHMIDT W., 1999. Mechanisms and regulation of reduction-based iron uptake in plants. New Phytol. 141, 1-26.

Sun H., Feng F., LiU J., Zhao Q., 2017. The interaction between auxin and nitric oxide regulates root growth in response to iron deficiency in rice. Front. Plant Sci. $8,2169$.

Von Wirén N., Bennett M.J., 2016. Crosstalk between gibberellin signalling and iron uptake in plants: an Achilles' Heel for modern cereal varieries? Dev. Cell 37, 110-111.

Wu T., Zhang H-T., Wang Y., Jia W-S., Xu X-F., ZhANG X-Z., ET AL., 2012. Induction of root Fe (III) reductase activity and proton extrusion by iron 
deficiency is mediated by auxin-based systemic signalling in Malus xiaojinensis. J. Exp. Bot. 63, 859-870.

Zuchi S., Cesco S., Gottardi S., Pinton R., Römheld V., Astolfi S., 2011. The rot-hairless barley mutant brb used as model for assessment of role of root hairs in iron accumulation. Plant Physiol. Biochem. 49, 506-512.

Zuchi S., Cesco S., Varanini Z., Pinton R., Astolfi S., 2009. Sulphur deprivation limits Fe-deficiency responses in tomato plants. Planta 230, 85-94.

Received September 6, 2018; accepted January 24, 2019 